\title{
SANKSI PIDANA TERHADAP PEMBUAT STIKER PRNOGRAFI DI MEDIA KOMUNIKASI WHATSHAP
}

\author{
Putu Bagus Dio Adinatha, Anak Agung Sagung Laksmi, I Made Minggu Widyantara \\ Fakultas Hukum Universitas Warmadewa, Denpasar-Bal, Indonesia \\ dioadinatha3@gmail.com, laksmidewi29@gmail.com, mademinggu21@gmail.com
}

\begin{abstract}
Abstrak
Penyebaran konten pornografi tidak hanya menyebar melalui akses halaman-halaman di website internet tetapi tersebar melalui berbagai platform, salah satunya adalah media komunikasi. Saat ini mayoritas masyarakat dari berbagai kelompok umur dan ekonomi sudah sangat mengenal media komunikasi online. Penelitian ini bertujuan untuk mengkaji pengaturan hukum terhadap pembuat stiker pornografi di media komunikasi whatshap dan mengkaji sanksi pidana terhadap pembuat stiker pornografi di media komunikasi whatshap. Jenis penelitian ini menggunakan hukum normatif dengan pendekatan Legislatif dan Konseptual. Sumber bahan hukum terdiri dari sumber bahan hukum primer, sekunder dan tersier. Dapat diperoleh melalui teknik inventarisasi atau penelusuran bahan hukum yang relevan dan kemudian diklasifikasikan atau dikelompokkan dan didokumentasikan, dicatat, dikutip, diringkas. Hasil penelitian menunjukkan bahwa pengaturan hukum pembuat stiker pornografi di media komunikasi WhatsApp diatur dalam UU ITE (Informasi dan Transaksi Elektronik) UU Nomor 11 Tahun 2008, KUHP (KUHP) dan UU Pornografi - Undang-Undang Nomor 44 Tahun 2008 yang dapat menjerat pelaku pembuat stiker pornografi di media komunikasi WhatsApp. Sanksi pidana terhadap pembuat stiker pornografi pada media komunikasi whatshap, setiap orang yang dengan sengaja dan tanpa hak menyebarkan informasi yang bertujuan menimbulkan kebencian atau permusuhan kepada individu dan/atau kelompok masyarakat tertentu berdasarkan suku, agama, ras, dan antargolongan (SARA), akan dikenakan sanksi pidana dengan pidana penjara paling lama enam tahun atau denda paling banyak Rp. 1 Milyar.
\end{abstract}

Kata kunci: Sanksi Pidana, Stiker Pornografi, Whatshapp

\section{Abstract}

The spread of pornographic content is not only spread through access to pages on the internet website but is spread through various platforms, one of which is communication media. Currently, the majority of people from various age groups and economies are very familiar with online communication media. This study aimed to examine the legal arrangements against pornographic sticker makers in WhatsApp communication media and examine criminal sanctions against pornographic sticker makers in WhatsApp communication media. This type of research used normative law with a Legislative and Conceptual approach. Sources of legal materials consisted of primary, secondary, and tertiary sources of legal materials. It could be obtained through an inventory or tracing technique of relevant legal materials and then classified or grouped and documented, recorded, quoted, summarized. The results of the study showed that the legal arrangements for making pornographic stickers on WhatsApp communication media are regulated in the ITE Law (Electronic Information and Transactions) Law No. 11 of 2008, the Criminal Code (KUHP), and the Pornography Law - Law No. 44 of 2008 which can ensnare the perpetrators of pornographic sticker makers on WhatsApp communication media. Criminal sanctions against pornographic sticker makers on WhatsApp communication media, any person who intentionally and without rights spreads information that aims to cause hatred or hostility to certain individuals and/or community groups based on ethnicity, religion, race, and intergroup (SARA), will be subject to criminal sanctions with a maximum imprisonment of six years or a maximum fine of Rp. 1 Billion.

Keywords: Criminal Sanctions, Pornographic Stickers, Whatsapp

\section{PENDAHULUAN}

Berdasrkan Pasal 1 ayat (3) Undang-undang Dasar Negara Republik Indonesia tahun 1945, yang berbunyi Negara Indonesia adalah Negara Hukum yang artinya negara yang memegang kekuasaan hukum tertinggi untuk menegakkan kebenaran dan keadilan, serta tidak ada kekuasaan yang tidak dipertanggungjawabkan (Mustafa, 2011). Ilmu Pengetahuan 
dan Teknologi dewasa ini berkembang sangat pesat, salah satunyan perkembangan ilmu pengetahuan dan teknologi di bidang media komukasi. Peradaban dunia masa kini dicirikan dengan fenomena kemajuan teknologi informasi dan globalisasi yang berlangsung hampir di semua bidang kehidupan. Apa yang disebut dengan globalisasi pada dasarnya bermula dari awal abad ke 20, yakni pada saat terjadi revolusi transportasi dan elektronika Universitas Sumatera Utara 2 yang menyebarluaskan dan mempercepat perdagangan antar bangsa, disamping pertambahan dan kecepatan lalu lintas dan jasa (Urbanus \& Febianti, 2017).

Kemajuan teknologi informasi (internet) dan segala bentuk manfaat di dalamnya membawa konsekuensi negatif tersendiri dimana semakin mudahnya para penjahat untuk melakukan aksinya yang semakin merisaukan masyarakat. Penyalahgunaan yang terjadi dalam cyber space inilah yang kemudian dikenal dengan cyber crime atau dalam literatur lain digunakan istilah computer crime”. Maskun, (2011) Internet telah membentuk masyarakat dengan kebudayaan baru, Masyarakat baru dengan kebebasan beraktifitas dan berkreasi degan cara yang mudah. Kemajuan teknologi informasi telah mengubah pandangan manusia tentang berbagai kegiatan yang selama ini hanya di monopoli oleh aktivitas yang bersifat fisik belaka. Lahirnya internet mengubah paradigma komunikasi manusia dalam bergaul, berbisnis dan juga berasmara (Rahardjo, 2002). Hal tersebut telah mengubah alur berkembangnya tindakan kejahatan yang dilakukan oleh masyarakat sehingga memunculkan kejahatan dalam bentuk "cyber crime". Ditandai dengan berkembang pesatnya situs-situs porno dalam berbagai tampilan situs yang sangat menggiurkan. Bahkan dalam berbagai data terakhir menunjukan bahwa tranksaksi terbesar perdagangan melalui internet diperoleh melalui bisnis pornografi ini (Makarim, 2003). Hal tersebut kini dikenal dengan istilah "cyber pornography".

Perkembangan pornografi yang semakin marak tidak lepas kaitannya dengan perkembangan teknologi komunikasi saat ini. Pornografi yang pada awalnya hanya didistribusikan melalui video Betacam kemudian keping Digital Versatile Disk (DVD) maupun Versatile Compact Disk (VCD), saat ini dapat dikonsumsi melalui laptop, tablet, smartphone, serta perangkat digital lainnya dengan didukung oleh koneksi internet. Dampak dari pornografi sendiri saat ini dapat dilihat dari seringnya terjadi kasus perzinahan, pembunuhan, aborsi, dan pemerkosaan. Lalu tak hanya orang dewasa yang menjadi korban dari pornografi tersebut melainkan juga melibatkan anakanak dibawah umur dimana pornografi itu menyebabkan penyimpangan seksual dan menjadi penyebab terkikisnya nilai nilai budaya dan moral untuk generasi bangsa. Peredaran konten pornografi tidak hanya tersebar melalui akses lamanlaman di website internet tetapi disebarkan melalui berbagai platform salah satunya adalah media komunikasi yang pada dasarnya digunakan untuk keperluan berbagi informasi, lokasi, file, foto, video dan sebagainya.

Perkembangan teknologi saat ini memberikan dampak negatif dengan munculnya berbagai jenis pelanggaran dan bahkan suatu kejahatan seperti cyber pornography (Ngafifi, 2014). Kejahatan dalam kehidupan manusia merupakan gejala sosial yang akan selalu dihadapi oleh setiap manusia, masyarakat, bahkan Negara (Ummah, 2017). Kenyataannya telah membuktikan bahwa kejahatan hanya dapat dicegah atau dikurangi tetapi sulit untuk diberantas secara tuntas. Kejahatan seperti penyerbaran pornograpi perlu mendapat perhatian secara serius mengingat kerugian yang dapat ditimbulkan yang dampaknya akan berakibat merugikan Negara, masyarakat maupun individu (Chazawi, 2016). Oleh karena itu Negara memberikan reaksi berupa larangan terhadap perbuatan melawan hukum serta sanksi bagi pelanggarnya. Perbuatan atau kejahatan yang perlu mendapatkan perhatian serius pada saat ini yaitu penyebaran konten pornografi yang dilakukan melalui akses media komunikasi.Penegakan hukum terhadap suatu masalah hukum, baru dapat dilakukan bila ada hukum yang harus ditegakan atau diterapkan. Penguasa dalam penegakan hukum dapat menjatuhkan hukum kepada seseorang atas perbuatan yang dilakukannya (Hendro Setyo Wahyudi, 2014). Penyalahgunaan fungsi media komunikasi menjadi tempat tersebarnya konten kesusilaan semakin hari semakin meningkat. Meningkatnya penyalahgunaan ini perlu dibarengi dengan tindakan pencegahan, pengurangan, dan penjatuhan sanksi terhadap segala bentuk penyalahgunaan tersebut. 
Berdasarkan uraian dari beberapa penelitan terdahuu maka penelitian saat ini dilakukan untuk mengkaji pengaturan hukum terhadap pembuat stiker pornografi di media komunikasi whatshap dan menelaah sanksi pidana terhadap pembuat stiker pornografi di media komunikasi whatshap.

\section{METODE PENELITIAN}

Penelitian ini didesain denngan penelitian hukum normatif yaitu menganalisis kepustakaan berdasarkan bahan hukum yang digunakan yaitu baik primer, sekunder dan tersier. Sedangkan pendekatan masalah yang digunakan dalam penelitian ini adalah pendekatan perundang-undangan dan pendekatan Konseptual. Sumber bahan hukum terdiri dari sumber bahan hukum primer, sekunder dan tertier, teknik pengumpulan bahan hukum dengan teknik inventarisasi atau penelusuran bahan hukum yang bersangkutan lalu diklasifikasi atau dikelompokan dan didokumentasikan, dicatat, dikutip, diringkas, diulas sesuai kebutuhan dengan pendekatan kualitatif. Menganalisis penelitian ini menggunakan teknik bersifat sistematis dengan disajikan secara deskriptif-analitis, yaitu dengan mendeskripsikan bahan hukum terlebih dahulu secara sistematis kemudian menganalisa melalui teknik analisis dengan teknik tafsiran dan menggunakan argumentasi yang bertumpu pada logika hukum dengan deduktif-induktif.

\section{HASIL DAN PEMBAHASAN}

\section{Pengaturan Hukum Terhadap Pembuat Stiker Pornografi di Media Komunikasi Whatshap}

Kehadiran internet sebagai sebuah fenomena kemajuan teknologi menyebabkan terjadinya percepatan globalisasi dan lompatan besar bagi penyebaran informasi dan komunikasi di seluruh dunia. Penggunaan internet sebagai media informasi multimedia membuat beragam karya digital dapat secara terus-menerus digandakan dan disebarluaskan ke ribuan orang dalam waktu singkat, hanya dengan mencari keynote tertentu tidak heran jika internet dipandang sebagai lautan informasi (Isnaini, 2009). Perkembangan teknologi informasi ini di satu sisi akan mempermudah manusia dalam menjalankan aktivitasnya, di sisi lain dapat menimbulkan berbagai masalah yang memerlukan penanganan yang serius, seperti munculnya berbagai bentuk kejahatan baru yang dikenal dengan cyber crime (Mansur \& Gultom, 2005).

Dunia maya ini memiliki aturan (kelaziman) yang di definisikan bersama. Aturan ini ada yang sama da nada yang berbeda dengan aturan yang ada di dunia nyata dikarenakan hukum-hukum fisika tidak berlaku di dunia ini. Dua orang yang secara fisik berbeda di tempat yang jaraknya ribuan kilometer dapat berada di ruang virtual yang sama. Hal itu mengisyaraktkan, bahwa dunia maya yang dibangun atau di kontruksikan melalui jaringan internet dapatlah membangun daya rangsang dan emosi besar penggunanya. Di satu sisi, pengguna internet dapat memenuhi kepuasan psikologinya ketika problem yang dihadapinya dapat diselesaikan dengan jasa internet. Di sisi lain, mereka dapat memilih informasi yang sekedar memuaskannya, meskipun di beberapa hal bertolak belakang dengan norma hukum dan agama (Wahid \& Labib, 2005).

Istilah pornografi merupakan suatu kata serapan dari bahasa Inggris yang telah masuk ke dalam perbendaharaan kata bahasa Indonesia (Wirawan, 2013). Dalam Black's Law Dictionary memberikan pengertian bahwa pornografi adalah semua materi yang bermuatan seksual dengan tujuan untuk meningkatkan atau menimbulkan nafsu seksual bagi penikmatnya. Webster's Third International Dictionary mendefiniskan bahwa Pornografi terdiri dari dua kata asal, yaitu porno dan grafi. Porno berasal dari kata Yunani yaitu porne artinya pelacur dan grafi bersal dari kata graphein yang artinya ungkapan”. (expression). Perkembangan teknologi informasi dan teknologi membawa banyak manfaat dalam hal pemanfaatan transaksi bisnis namun adakalanya dunia virtual hanya dimanfaatkan sebagai tempat seorang netizen berinteraksi layaknya dunia nyata. Dunia virtual juga memiliki permasalahan yang timbul sebagai akibat dari penyalahgunaan teknologi itu sendiri yang akhirnya menimbulkan persoalan hukum. Masyarakat yang sadar akan penyalahgunaan teknologi internet akhirnya menginginkan sebuah pengaturan yang jelas akan dunia virtual ini. Permasalahan susila yang awalnya dirasakan hanya ada di dunia nyata akhirnya sedikit banyak mulai terbawa ke dunia virtual. Korban dari perbuatan asusila di dunia virtual ini bisa saja anak-anak di bawah umur bahkan remaja. Situs-situs porno yang bertebaran di dunia virtual membuat banyak para pihak yang seharusnya belum layak untuk mengaksesnya malah melakukan browsing ke situs itu. 
Telah ada payung hukum yang jelas dalam penegakan hukum terhadap tindak pidana pornografi lewat media komunikasi elektronik ini dengan adanya Undang-undang Nomor 11 Tahun 2008 tentang Informasi dan Transaksi Elektronik. Selain itu juga yang diatur dalam Kitab Undangundang Hukum Pidana (KUHP), Undang-undang Nomor 8 Tahun 1992 tentang Perfilman, Undangundang Nomor 36 Tahun 1999 tentang Telekomunikasi, Undang-undang Nomor 40 Tahun 1999 tentang Pers, Undang-undang Nomor 32 Tahun 2002 tentang Telekomunikasi dan Undang-undang Nomor 44 Tahun 2008 tentang Pornografi.

Pengaturan hukum terhadap pembuat stiker pornografi ini diatur di dalam KUHP dan Undang-undang Buku II Bab XIV yaitu Pasal 281 - 299 KUHP dan kejahatan pelanggaran terhadap kesusilaan diatur dalam Pasal 301, 504, 505 KUHP dan juga pada Buku III Bab VI dari Pasal 532- 547 KUHP hal ini menunjukan bahwa tindakan kejahatan kesusilaan merupakan suatu bentuk pelanggaran norma-norma hukum, agama, dan social. Tindak pidana pornografi bukan hanya diatur dalam Undang-undang Nomor 44 Tahun 2008 tentang Pornografi, namun terlebih dahulu pornografi diatur dalam Kitab Undang-undang Hukum Pidana (KUHP), Dalam KUHPidana.

\section{Sanksi Pidana Terhadap Pembuat Stiker Pornografi di Media Komunikasi Whatshap}

Sanksi merupakan suatu langkah hukuman yang dijatuhkan oleh negara atau kelompok tertentu karena terjadi pelanggaran yang dilakukan oleh seseorang atau kelompok. Sistem hukum pidana ada dua jenis sanksi yang mempunyai kedudukan yang sama, yaitu sanksi pidana dan sanksi tindakan. Sanksi pidana merupakan jenis sanksi yang paling banyak digunakan di dalam menjatuhkan hukuman terhadap seseorang yang dinyatakan bersalah melakukan perbuatan pidana (Ali, 2011).

Black's Law Dictionary Henry Campbell Black memberikan pengertian sanksi pidana sebagai punishment attached to conviction at crimes such fines, probationand sentences (suatu pidana yang dijatuhkan untuk menghukum suatu penjahat (kejahatan) seperti dengan pidana denda, pidana pengawasan dan pidana penjara). Sanksi pidana adalah bentuk sanksi yang paling banyak digunakan dalam menjatuhkan hukuman kepada seseorang yang terbukti bersalah melakukan perbuatan pidana. Bentuk-bentuk sanksi pidana juga bervariasi, seperti pidana mati,pidana seumur hidup, pidana penjara, pidana kurungan, dan pidana denda yang merupakan pidana pokok, serta pidana berupa pencabutan hak-hak tertentu, perampasan barangbarang tertentu dan pengumuman putusan hakim yang keseluruhannya merupakan pidana tambahan.

Beberapa materi perbuatan yang dilarang (cybercrimes) yang diatur dalam UU ITE, meliputi konten ilegal seperti kesusilaan, perjudian, penghinaan atau pencemaran nama baik, pengancaman dan pemerasan (Pasal 27, Pasal 28, dan Pasal 29 UU ITE). Akses ilegal (Pasal 30); Intersepsi ilegal (Pasal 31); Gangguan terhadap data (data interference, Pasal 32 UU ITE); Gangguan terhadap sistem (system interference, Pasal 33 UU ITE); penyalahgunaan alat dan perangkat (misuse of device, Pasal 34 UU ITE).

Sanksi dalam Undang-undang ITE yang menjerat pelaku pembuat stiker pornograi di media komunikasi whatshapp:

Pasal 27

(1) Setiap orang dengan sengaja dan tanpa hak mendistribusikan atau mentransmisikan atau membuat dapat diaksesnya informasi elektronik atau dokumen elektronik yang memiliki muatan yang melanggar kesusilaan.

(2) Setiap orang dengan sengaja dan tanpa hak mendistribusikan atau mentransmisikan atau membuat dapat diaksesnya informasi elektronik atau dokumen elektronik yang memiliki muatan perjudian.

(3) Setiap orang dengan sengaja dan tanpa hak mendistribusikan atau mentransmisikan atau membuat dapat diaksesnya informasi elektronik atau dokumen elektronik yang memiliki muatan penghinaan atau pencemaran nama baik.sengaja dan tanpa hak mendistribusikan atau mentransmisikan atau membuat dapat diaksesnya informasi elektronik atau dokumen elektronik yang memiliki muatan pemerasan dan/atau pengancaman. 
Pasal 28

(1) Setiap orang dengan sengaja dan tanpa hak menyebarkan berita bohong dan menyesatkan yang mengakibatkan kerugian konsumen dalam transaksi elektronik.

(2) Setiap orang dengan sengaja dan tanpa hak menyebarkan informasi yang ditujukan untuk menimbulkan rasa kebencian atau permusuhan individu atau kelompok masyarakat tertentu berdasarkan atas suku, agama, ras, dan antargolongan. (SARA).

Sanksi pidana terhadap pembuat stiker pornografi di media komunikasi whatshap, sesuai dengan Pasal 27 ayat (1) Setiap Orang yang memenuhi unsur sebagaimana dimaksud dalam Pasal 27 ayat (1), ayat (2), ayat (3), atau ayat (4) dipidana dengan pidana penjara paling lama enam tahun atau denda paling banyak Rp1.000.000.000,00 (satu miliar rupiah). Dan diancam sesuai dengan bunyi Pasal 28 ayat (2) UU ITE, setiap orang yang dengan sengaja dan tanpa hak menyebarkan informasi yang ditujukan untuk menimbulkan rasa kebencian atau permusuhan individu atau kelompok masyarakat tertentu berdasarkan atas suku, agama, ras, dan antargolongan (SARA) akan dipidana dengan pidana penjara paling lama enam tahun atau denda paling banyak Rp1 miliar.

\section{SIMPULAN DAN SARAN}

\section{Simpulan}

Berdasarkan hasil analisis data diketahui bahwa Pengaturan hukum terhadap pembuat stiker pornografi diatur dalam Undang-undang ITE (informasi dan transaksi elektronik) Undang-undang Nomor 11 tahun 2008, KUHP (Kitab Undang-undang Hukum Pidana) serta Undang-undang Pornografi Undang-Undang Nomor44 Tahun 2008 yang dapat menjerat pelaku pembuat stiker pornografi di media komunikasi whatsap. Sanksi pidana terhadap pembuat stiker pornografi di media komunikasi whatshap, sesuai dengan Pasal 27 ayat (1) Setiap Orang yang memenuhi unsur sebagaimana dimaksud dalam Pasal 27 ayat (1), ayat (2), ayat (3), atau ayat (4) dipidana dengan pidana penjara paling lama enam tahun atau denda paling banyak Rp1.000.000.000,00 (satu miliar rupiah). Dan diancam sesuai dengan bunyi Pasal 28 ayat (2) UU ITE, setiap orang yang dengan sengaja dan tanpa hak menyebarkan informasi yang ditujukan untuk menimbulkan rasa kebencian atau permusuhan individu dan/atau kelompok masyarakat tertentu berdasarkan atas suku, agama, ras, dan antargolongan (SARA) akan dipidana dengan pidana penjara paling lama enam tahun atau denda paling banyak Rp1 miliar.

\section{Saran}

Sesuai simpulan penelitian, maka peneliti memberi saran kepada pemerintah melalui aparat penegak hukum, agar menindak dengan tegas para pelaku cyber crimedimana dalam khasus yang saya buat melalui skripsi ini yang berjudul "sanksi pidana terhadap pembuat stiker pornografi di media komunikasi whatsshap" supaya masyarakat lebih mengerti mengenai pengaturan sanksi dan penegakan hukum dalam uu ite dan pornografi. dalam hal melakukan tindakan pencegahan tersebut pemerintah dapat melakukan sosialisasi kepada masyarakat, karena sekarang kita ditengah era globalisasi, dimana sitem informasi teknologi dan komunikasi tersebut sangat berpengaruh terhadap kehidupan kita sekarang. Dan supaya kejahatan mengenai sitem informasi teknologi dan komunikasi pada kalangan masyarakat lebih terkendali dan tidak terjadi. Kepada Masyarakat agar lebih cerdan dan bermoral dalam menggunakan ITE serta mengenai pornografi karna pada era globalisasi sekarang sistem informasi teknologi dan komunikasi sangat berpengaruh dalam kehidupan sehari-hari di dalam lingkuan masyarakat, instansi sekolah, kampus, serta kantoran dan khususnya kepada masyarakat milenial sekarang jangan mudah terpengaruhi dan cepat menyebarkan dengan berita yang terdapat pada media apapun, karna dari situlah dapat timbul khasus mengenai sitem informasi komunikasi dan teknologi.

\section{DAFTAR PUSTAKA}

Ali, M. (2011). Pengawasan Peredaran Barang Cetakan, Due Process Of Law dan Hak Atas Kebebasan Mengeluarkan Pendapat. Jurnal Konstitusi, 8(4), 521-550.

Chazawi, A. (2016). Tindak Pidana Pornografi. Jakarta Timur. Sinar Grafika.

Hendro Setyo Wahyudi, M. P. S. (2014). Teknologi dan Kehidupan Masyarakat. Jurnal Analisa Sosiologi, 3(1), 13-24.

Isnaini, Y. (2009). Hak Cipta dan Tantangannya di Era Cyber Space. Ghalia Indonesia: 
Jakarta.

Makarim, E. (2003). Komplikasi Hukum Telematika. Jakarta: PT Raja Grafindo Persada.

Mansur, D. M. A., \& Gultom, E. (2005). Cyber Law-Aspek Hukum Teknologi Informasi. Bandung: Refika Aditama.

Maskun. (2011). Kejahatan Siber Cyber Crime, . Media Pustaka.

Mustafa, B. (2011). Sistem Hukum Administrasi Negara Indonesia. Citra Aditya Bakti.

Ngafifi, M. (2014). Kemajuan Teknologi Dan Pola Hidup Manusia Dalam Perspektif Sosial Budaya. Jurnal Pembangunan Pendidikan: Fondasi Dan Aplikasi, 2(1), 33-47.

Rahardjo, A. (2002). Cyber Crime Pemahaman dan Upaya Penanggulangan Kejahatan Berteknologi. Bandung. Citra Aditya Bhakti.

Ummah, S. R. (2017). Pornografi Ditinjau dari Hukum Positif dan Hukum Pidana Islam. Jurnal Pemikiran Dan Pembaharuan Hukum Islam, 2(2), 26-35.

Urbanus, N., \& Febianti. (2017). Analisis Dampak Perkembangan Pariwisata terhadap Perilaku Konsumtif Masyarakat Wilayah Bali Selatan. Jurnal Kepariwisataan Dan Hospitalitas, 1(No.2), 118-133.

Wahid, A., \& Labib, M. (2005). Kejahatan Mayantara (Cyber Crime),. Bandung. PT.Rafika Aditama.

Wirawan, N. (2013). Pertanggungjawaban Pidanan Terhadap Penayangan Pornografi Dalam Dunia Maya Menurut UU No.4 Tahun 2008 Tentang Pornografi. Jakarta: Sinar Grafika. 